\title{
Enablers and barriers in adopting a reablement model of domiciliary care
}

DOI:

10.1108/JICA-07-2020-0045

\section{Document Version}

Accepted author manuscript

Link to publication record in Manchester Research Explorer

\section{Citation for published version (APA):}

King, E., \& Young, A. (2021). Enablers and barriers in adopting a reablement model of domiciliary care. Journal of Integrated Care. https://doi.org/10.1108/JICA-07-2020-0045

\section{Published in:}

Journal of Integrated Care

\section{Citing this paper}

Please note that where the full-text provided on Manchester Research Explorer is the Author Accepted Manuscript or Proof version this may differ from the final Published version. If citing, it is advised that you check and use the publisher's definitive version.

\section{General rights}

Copyright and moral rights for the publications made accessible in the Research Explorer are retained by the authors and/or other copyright owners and it is a condition of accessing publications that users recognise and abide by the legal requirements associated with these rights.

\section{Takedown policy}

If you believe that this document breaches copyright please refer to the University of Manchester's Takedown Procedures [http://man.ac.uk/04Y6Bo] or contact uml.scholarlycommunications@manchester.ac.uk providing relevant details, so we can investigate your claim.

\section{OPEN ACCESS}




\section{Enablers and barriers in adopting a reablement model of domiciliary care}

Erin King

Alys Young

To appear in The Journal of Integrated Care.

2021 


\section{Abstract}

\section{Purpose}

This paper explores the effectiveness of reablement as an outcome-focussed commissioning model within the English domiciliary care market from the perspective of two private domiciliary care agency (PDCA) managers/owners within one Local Authority (LA) in the North West of England. Specifically, it focusses on owner/managers' perceived ability to effect change from a dependency to a reablement model within the English domiciliary care market.

\section{Design/ methodology/ approach}

Qualitative interviews with 2 contrasting owners/managers of PDCAs within one LA in the North West of England were carried out. Explorative analysis followed a constructionist grounded theory methodology.

\section{Findings}

Findings revealed how two main factors interacted to effect change from a dependency model to a reablement model of domiciliary care: internal organisational structure and individual emotional investment of the owners/managers. Additionally, fiscal and external organisational systems impact on these drivers, and are perceived to act as potential barriers to the adoption of a reablement model of domiciliary care by PDCAs.

\section{Originality/value}

Although based on only two idiographic accounts, the findings shed light on the policy and practice of commissioning models of domiciliary care within England and suggest further studies in this area of practice. 


\section{Keywords}

Reablement, domiciliary care, grounded theory, commissioning

\section{Paper type}

Research paper

\section{Introduction}

This article reports a small exploratory study into the effectiveness of reablement as an outcome-focussed commissioning model within the English domiciliary care market, from the perspective of private domiciliary care agency (PDCA) owners/managers of within a chosen Local Authority (LA) in the North West of England.

Reablement is a short term, preventive domiciliary care service where care workers do self-care tasks with recipients of the service rather than doing the tasks for recipients, in contrast to a traditional dependency model of domiciliary care (Glendinning and Newbronner, 2008). Reablement epitomises a key strand in the UK political agenda over the past 14 years aimed at improving economic and process of care efficiencies to alleviate pressures on hospital intake and discharge services and promote the integration of health and social care services (Department of Health, 2006, 2010).

In addition to economic and process of care efficiencies, the political agenda has been shaped by the current personalisation agenda within adult social care (Government, 2012; Rabiee and Glendinning, 2011). These trends have resulted in models of care underpinned by the promotion of independence and the provision of choice and control for those who use services; from the 'new vision' of Blair's Labour government to the recent NHS Long Term Plan (Department of Health, 2005: 6; National Health Service, 2019). Reablement, therefore, epitomises both the political agenda of the past 14 years 
and the current philosophical context for adult social care. Accordingly, reablement may be regarded not only as a domiciliary care service but a philosophical approach to domiciliary care that has led to recommendations for the development of a 'reablement culture' across adult social care services (Newbronner et al., 2007).

Consequently, the Government has encouraged outcome-focussed commissioning via payment by results models within the independent domiciliary care market (Bolton, 2015; HM Government, 2011). Findings, from the limited research undertaken to date, suggest payment by results models have raised challenges for this market, with PDCAs being expected to innovate and accept flexible commissioning models (Baxter et al., 2011; Bolton, 2015). The aim of this study was to explore the effectiveness of reablement as an outcome-focused commissioning model within the English domiciliary care market; focussing specifically on owner/managers' perceived ability to effect change from a dependency to a reablement model.

\section{Method}

\section{Setting, participants and data collection}

Data were collected by means of a single semi-structured individual interview that was digitally recorded and transcribed. All owner/managers of PDCAs, identified on a chosen North West of England LA website, were contacted to participate in the research $(\mathrm{n}=41)$. Only those PDCAs providing domiciliary care to adults 18 years old and over and registered with the Care Quality Commission at the time of recruitment were included. Two participants volunteered for the study - a registered manager and an owner of a PDCA. This was fewer than anticipated with likely reasons including the 
Christmas period and associated winter pressures on health and social care during the recruitment phase.

\section{Analysis}

A qualitative approach using a constructionist grounded theory methodology was adopted within the study. Informed by the work of Thornberg (2012) and Timmermans and Tavory (2012), the analysis process was both inductive and abductive involving recourse to literature reviews during the process of analysis to theoretically interrogate the provisional findings and develop them further to new layers of analysis. This included referencing similar issues in a different or contrasting context to confirm or challenge the extent to which the provisional findings had context-specific derivation or saliency. The findings proceed by way of provisional 'model building' reflecting how additional layers of analysis using this methodology resulted in new understandings of how the factors identified interacted. Inferences drawn from the analysis are regarded as partial rather than conclusive.

\section{Findings}

The presentation of findings is organised to reflect the interaction between different aspects of individual (both personal and context-specific), internal (organisational) and

external structures. As the analysis progresses, figures illustrate the potential structural influences on the ability of PDCA owners/managers to effect change from a dependency model of domiciliary care to a reablement model.

\section{Individual structures}

(i) Mentality, empathy and emotional investment 
The individual mentality of the participant emerged during the coding of data as a key influence in seeking to effect change in the context of implementing a reablement model of domiciliary care. Mentality encompassed attitude, feeling and behaviour, which characterised the working approach of each owner/manager and was evident in the interviews through either the participants' specific reference to it or implied through the analysis of their contributions. Both participants revealed a genuine care for their clients and spoke about themselves as 'natural' carers who 'carried it through' from their personal lives into their paid work. Their mentality was evident in their empathic choice of words about their clients, and their emotional investment in their work. When expressing empathy, a similar trait both participants adopted was to individualise client situations; however, the focus of each participant's empathy differed depending on what they regarded as salient. Participant 1 was empathetic towards the personal circumstances of clients that had resulted in them entering the health and social care system, whereas Participant 2 voiced empathy towards their client's ability to navigate the consequences of the health and social care system for their everyday life:

"You can get a client that wants a 7 o'clock in the morning call but we haven't got a gap 'til 9 (.) but they have to take that because that's all they've got available. So then they're staying in bed for an extra few hours when, you know, th...their whole life th...they've got up at 7 o'clock (.) that's just something that you can't, you know..." [Participant 2] 
The participants' empathy towards their clients regularly led them to use emotive language; either as an expression of their inward emotions and personal investment in their work, or as an outward expression of frustration or incredulity at the barriers they felt the health and social care system placed on their roles:

"I do feel bad saying no to people" [Participant 2]

Both participants said that their work was 'not an easy career' [Participant 1] and involved 'just [doing] your best' [Participant 2]. However, neither participant expressed dissatisfaction with their choice of career, suggesting the personal investment in their work was strong enough to overcome potential barriers.

The significance of mentality, empathy and emotional investment as traits in a manager's ability to address potential barriers to effective change was investigated in the wider literature.

Existing literature, although not specific to PDCA managers, affirmed the findings above (Beresford et al. 2011; Ellis et al. 2014; Ross et al. 2016). Positive change mechanisms identified in the literature - a caring nature and a genuine desire to help those they support (Beresford et al. 2011, p.26; Ross et al. 2016, p.4) - appear to influence the manner in which the participants approached the development of positive relationships with clients, their staff and other professionals within the health and social care sector.

\section{(ii) Relationships}

Both participants said knowledge of the client, PDCA staff and of the wider health and social care sector informed the positive relationships they developed to effect change. 
They identified that through developing positive relationships in these three key areas they could develop knowledge of their clients which they linked with mitigation of potential dependency by clients on the health and social care system.

There were various mechanisms for this. For instance, Participant 2 regarded good relationships between clients and the PDCA as being key to tuning into client preferences and ultimately offering more choice that might enhance independence forming habits. Participant 1, however, referred to the holistic client knowledge that arises through good relationships with PDCA staff. They defined their role as an owner of a PDCA as having 'to trust their staff explicitly' so, they will have a knowledge of their staff 'strengths' and the type of work they enjoy with the purpose of getting the best from their staff to meet the care needs of the client and address the difficulties faced by the PDCA in staff recruitment and retention.

Therefore, effective change was understood by both participants as leading from a shared vision by more than one person rather than on an individual basis; with both participants identifying a knowledge of professional roles within health and social care as being beneficial 'to get the same outcome' for the client.

The participants' assertions were explored within literature to find whether knowledge of roles between different professionals affects the development of positive relationships within a reablement model of domiciliary care. The literature suggested that PDCA owner/managers who collaborate with other professionals external to their organisation may develop a deeper knowledge of not only other professionals' roles but their own role within 'the system' (Birkeland et al., 2017; Duner, 2013; Hjelle et al., 2016; Randstrom et al., 2014). However, collaboration within the literature referred to either 
interdisciplinary or interprofessional working, unlike the participants' experience of collaboration as multidisciplinary working, which involved professionals working independently but sharing information (Moe and Brataas, 2016; Steihaug et al., 2014). Nevertheless, if PDCA owner/managers were able to develop a deeper knowledge of their role within 'the system' they may be able to counter the dependency model of domiciliary care by providing an holistic response to clients that supports a reablement model of domiciliary care (Duner, 2013; Hjelle et al., 2016).

\section{Interaction between individual and internal structures}

Although both participants had a similar mentality to overcoming barriers within their work, they spoke about their ability to effect change differently. Participant 1 spoke enthusiastically about change as if it were a constant, self-perpetuating forward motion using phrases such as 'knock on effect', and 'growing things'. This contrasted with Participant 2 who pointed to barriers over which she felt she lacked control, such as availability of care workers, a rising demographic of older people and increased demand for domiciliary care. Although Participant 1 recognised the same barriers as Participant 2, she approached these barriers with a sense that she had the power to effect change.

Subsequently, in addition to the mentality of participants, the occupational position of the participants - the first was an owner, the second a manager - provided a further explanation for their ability to effect change. This initiated a literature search to understand the influence of occupational role on perceived individual agency to effect change within internal structures of PDCAs, as illustrated in Figure 1 and discussed below. 


\section{[Insert Figure 1]}

A clear message from existing literature was that middle managers in social care, such as Participant 2, are regarded as not having the authority to effect change in organisational policy (Lunts, 2012; Meynhardt and Metelmann, 2009). This lack of authority may be a result of organisational structures as explored by Kim (2011) in her $\mathrm{PhD}$ thesis studying the influence of organisational structure on effecting change within residential and home care agencies in the USA. Kim's findings show that an organic structure will enable middle managers to initiate change whereas a mechanistic structure will enable the implementation of change (Kim, 2011). Although mechanistic organisational structures can enable PDCA registered managers to implement change, it may result in a role conflict for them as they may be expected to innovate but not have the internal organisational structure around them to support this expectation (Kim, 2011; Lunts, 2012; Meynhardt and Metelmann, 2009). With the emotional investment that PDCA owner/managers have in their work the conflict in role for registered managers may be an added frustration compared with PDCA owners and result in them feeling a lack of control:

“I can't change that unfortunately ((laughing)) there's too much above me" [Participant 2]

Interaction between internal and external structures

In contrast to the above, other studies have found the authority to effect change was external to the PDCA (Denton et al., 2002; Payne and Leiter, 2013). Payne and Leiter (2013: 115) found that parent organisations, such as a PDCA franchise, can result in 
'coercive isomorphism and resource dependencies' that can restrict managers ability to effect change and result in a conflict within their role. This resonates with Participant 2 who discussed policies and procedures that the parent franchise enforced and which they were unable to change:

“...I can't change the policy doesn't matter who I speak to...it's not, you know, if I think it's right or not it...it's not gonna change [Participant 2]

Additionally, Payne \& Leiter's (2013) study compliments the findings in Kim's (2011) thesis of internal and external structural forces. Therefore, as Figure 2 illustrates, influences on effecting change toward a reablement model may not just come from within, but also from without, referred by the participants as 'the system' and 'they'.

[Insert Figure 2]

\section{(i) 'The System'}

The most significant external structure identified by participants was 'the system', a word which recurred in their narratives. They used it when talking about the commissioning of care from PDCAs, with associated monitoring of the commissioned care packages, assessment of a person's care needs, and application of internal PDCA policies.

Participant 1 called 'the system' a 'barrier' and 'frustrating' because it was 'restrictive' or inflexible in its capacity to deliver and fund commissioned care. The participants regarded such attributes as partially responsible for having created a dependent society 
through the creation of 'expectations' within service delivery by commissioners of domiciliary care, who the participants called 'they'.

\section{(ii) 'They'}

The participants talked about 'they' as being based within councils and/ or social services rather than health authorities and holding a powerful position over PDCAs by controlling PDCA income through the monitoring and commissioning of care visits. Both participants talked about 'they' as humans who administer 'the system', although neither participant referred directly to a specific person, role or organisation:

“...because as soon as they know we've got capacity we'll have (.) mo...more calls every day" [Participant 2]

'They' are faceless and both participants used a negative tone of voice when referring to 'they' that implied a difficult relationship. As Participant 1 explained 'they' don't listen that people are becoming dependent on care and Participant 2 stated that people 'battle' against 'they' and 'the system' to receive the care they want.

Subsequently, participants regarded 'the system' and 'they' as potential barriers to a reablement model of domiciliary care. Neither identified an individual or specific organisation as responsible for instigating a dependency on care. Instead both placed the responsibility for society's dependency on care on 'the system' and 'they'. To contextualise this attitude and assumptions a literature review addressed origins of dependency forming in domiciliary care. 
There is some literature that regards PDCAs as instigators of dependency within their client base. However, the wider international literature supports the perception that commissioning of domiciliary care is a factor in the institutionalisation of recipients of this service through fiscal and external organisational restrictions, that influence PDCA owner/managers' ability to effect change in two ways that are significant and complimentary (Clarke et al., 2011; Ranci and Pavolini, 2015). Firstly, the restrictive and inflexible approach of commissioning domiciliary care services has potentially adapted the behaviour of those in receipt of domiciliary care so they normalise restrictive commissioning (Hall and Taylor, 1996). This may impact on the PDCA owner/managers' ability to introduce a reablement model of domiciliary care to recipients who are passive and expect a dependent model of care. Secondly, commissioning of domiciliary care via assessments of need that are time and task orientated results in PDCA owner/managers being restricted in the length of visits and the type of support they can provide to clients (Aronson and Sinding, 2000; Jack, 1998).

\section{Discussion}

The findings and their critical interrogation through the wider literature led to the development of the provisional theoretical model in Figure 3, which illustrates the perceived ability of PDCA owner/managers to effect change from a dependency to a reablement model within the English domiciliary care market.

[Insert Figure 3] 
This model proposes that the internal PDCA organisational structure and individual emotional investment of the PDCA owner/managers are mediating variables, which can affect their ability to innovate and effect a change from a dependency model to a reablement model of domiciliary care. To effectively achieve this change, the model suggests PDCAs require a less mechanistic organisational structure to innovate and empower managers to effect change and one which acknowledges the significance of relationships both internally and externally that are brokered by and grow out of the characteristics of individual leader/managers. Consequently, this may imply for larger organisations, such as the PDCA franchise that employed Participant 2, an assessment of the responsiveness of their organisational structure to the legislative requirements for innovation within the Care Act 2014 be undertaken (Department of Health \& Social Care, 2020).

Equally, the PDCA owner/managers' emotional investment in their work is a potential enabler to the adoption of a reablement model of domiciliary care. However, the provisional theoretical model suggests that PDCA owner/managers' motivation to adopt more flexible outcome-focussed commissioning models of domiciliary care is conditional on the internal PDCA organisational structures and external structures, such as 'the system' and 'they', supporting them to effect the necessary change.

The ability of 'the system' and 'they' to support PDCA owner/managers is, however, a potential barrier to the adoption of a reablement model of domiciliary care. The findings suggest the restrictive nature of some domiciliary care commissioning has potentially led to the perpetuation of dependency models of domiciliary care. This could suggest for outcome-focussed commissioning in adult social care to be effective, a critical appraisal 
of the existing legislative requirements under the Care Act 2014, that created a power on LAs to commission responsive and preventative adult social care services, may need consideration (Department of Health \& Social Care, 2020).

Although theoretical saturation was not achieved within the study, by adopting an abductive analytic approach to grounded theory, the study was able to produce a depth of knowledge sufficient to conclude a synergy between individual, internal PDCA and external organisational structures relative to the agency of the participants. We acknowledge that the dynamics of individual agency within the organisational constraints and context identified, requires further investigation.

\section{Conclusion}

The aim of the study was to provisionally explore a current gap in research by harnessing the views of owner/managers of PDCAs, operating in a chosen LA in the North West of England, about their ability to effect change to a reablement model of domiciliary care. Although the provisional theoretical model offers new insights into the domiciliary care market, it is limited in the depth of knowledge generated because of the limited geographical scope of the study and only having two participants who held significantly different positions within their respective PDCAs. As such further research is required, using theoretical sampling of owner/managers of PDCAs, to ensure a sufficient depth of knowledge to conclude that the theoretical model generated within the study is internally robust and valid.

The study, however, is significant in so far as it strengthens the findings of existing literature; that a cultural shift is required across adult social care services to enable the 
adoption of a reablement model of domiciliary care. Additionally, the provisional theoretical model identifies factors, such as commissioner-provider relationships or leadership, that may influence the effectiveness of outcome focussed commissioning models within the current adult social care market and, therefore, suggest further research is required.

\section{Declaration of conflicting interests}

The Authors declare that there is no conflict of interest.

\section{Funding statement}

This research received no specific grant from any funding agency in the public, commercial, or not-for-profit sectors.

\section{References}

Aronson J and Sinding C (2000) Home Care Users' Experiences of Fiscal Constraints: Challenges and Opportunities for Case Management. Care Management Journals 2(4): pp.220-225.

Baxter K, Glendinning C and Greener I (2011) The implications of personal budgets for the home care market. Public Money \& Management 31(2): pp.91-98

Birkeland A, Tuntland H, Førland O, et al. (2017) Interdisciplinary collaboration in reablement-a qualitative study. Journal of Multidisciplinary Healthcare 10: pp.195203.

Bolton J (2015) Emerging practice in outcome-based commissioning for social care. Discussion paper, Oxford Brookes University, UK.

Clarke CL, Wilcockson J, Gibb CE, et al. (2011) Reframing risk management in dementia care through collaborative learning. Health \& Social Care in the Community 19(1): pp.23-32. 
Denton M, Zeytinoglu IU, Davies S, et al. (2002) Job stress and job dissatisfaction of home care workers in the context of health care restructuring. International Journal of Health Services 32(2): pp.327-357.

Department of Health (2005) Independence, Well-being and Choice: our vision for the future of social care for adults in England. London.

Department of Health (2006) Our Health Our Care Our Say; a new direction for community services. Cm6737. Norwich.

Department of Health (2010) The Operating Framework for the NHS in England 2011/12. UK Department of Health: 1-61.

Department of Health \& Social Care (2020) Care and support statutory guidance. Available at: https://www.gov.uk/government/publications/care-act-statutoryguidance/care-and-support-statutory-guidance (accessed 22/7/2020)

Duner A (2013) Care planning and decision-making in teams in Swedish elderly care: a study of interprofessional collaboration and professional boundaries. Journal of Interprofessional Care 27(3): pp.246-253.

Glendinning C and Newbronner E (2008) The effectiveness of home care reablement -developing the evidence base. Journal of Integrated Care 16(4): pp.32-39.

Hall PA and Taylor RCR (1996) Political Science and the Three New Institutionalisms. Political Studies XLIV: pp.936-957.

Hjelle KM, Skutle O, Førland O, et al. (2016) The reablement team's voice: a qualitative study of how an integrated multidisciplinary team experiences participation in reablement. Journal of Multidisciplinary Healthcare 9: pp.575-585.

HM Government (2011) Open Public Services White Paper. Norwich: The Stationary Office. 
HM Government (2012) Caring for our future: reforming care and support. London.

Jack R (1998) Institutions in community care. In: Jack R (ed.) Residential versus Community Care. Basingstoke: Macmillan Press Ltd, pp.10-40.

Jones KC, Baxter K, Curtis LA, et al. (2009) The Short-term Outcomes and Costs of Home Care Re-ablement Services. Interim Report. Social Policy Research Unit, University of York, UK.

Kim J (2011) Organizational structure and change process outcomes in facility-based and home-based long-term care. PhD Thesis, The Pennsylvania State University.

Lunts P (2012) Change management in integrated care: what helps and hinders middle managers - a case study. Journal of Integrated Care 20(4): pp.246-256.

Meynhardt T and Metelmann J (2009) Pushing the Envelope: Creating Public Value in the Labor Market: an empirical study on the role of middle managers. Intl Journal of Public Administration 32: pp.274-312.

Moe A and Brataas H V (2016) Interdisciplinary collaboration experiences in creating an everyday rehabilitation model: a pilot study. Journal of Multidisciplinary Healthcare 9: pp.173-182.

National Health Service (2019) The NHS Long Term Plan. Available at: https://www.longtermplan.nhs.uk/wp-content/uploads/2019/08/nhs-long-term-planversion-1.2.pdf (accessed 9 November 2020).

Payne J and Leiter J (2013) Structuring agency: examining healthcare management in the USA and Australia using organizational theory. Journal of Health Organization and Management 27(1): pp.106-126.

Rabiee P and Glendinning C (2011) Organisation and delivery of home care re-ablement: what makes a difference? Health and Social Care in the Community 19(5): pp.495503. 
Ranci C and Pavolini E (2015) Not all that glitters is gold: long-term care reforms in the last two decades in Europe. Journal of European Social Policy 25(3): pp.270-285.

Randstrom KB, Wengler Y, Asplund K, et al. (2014) Working with 'hands-off' support: a qualitative study of multidisciplinary teams' experiences of home rehabilitation for older people. International Journal of Older People Nursing 9: pp.25-33.

Steihaug S, Lippestad J-W, Isaksen H, et al. (2014) Development of a model for organisation of and cooperation on home-based rehabilitation - an action research project. Disability And Rehabilitation 36(7): pp.608-616.

Thornberg R (2012) Informed Grounded Theory. Scandinavian Journal of Educational Research 56(3): pp.243-259.

Timmermans S and Tavory I (2012) Theory Construction in Qualitative Research: from grounded theory to abductive analysis. Sociological Theory 30(3): pp.167-186. 


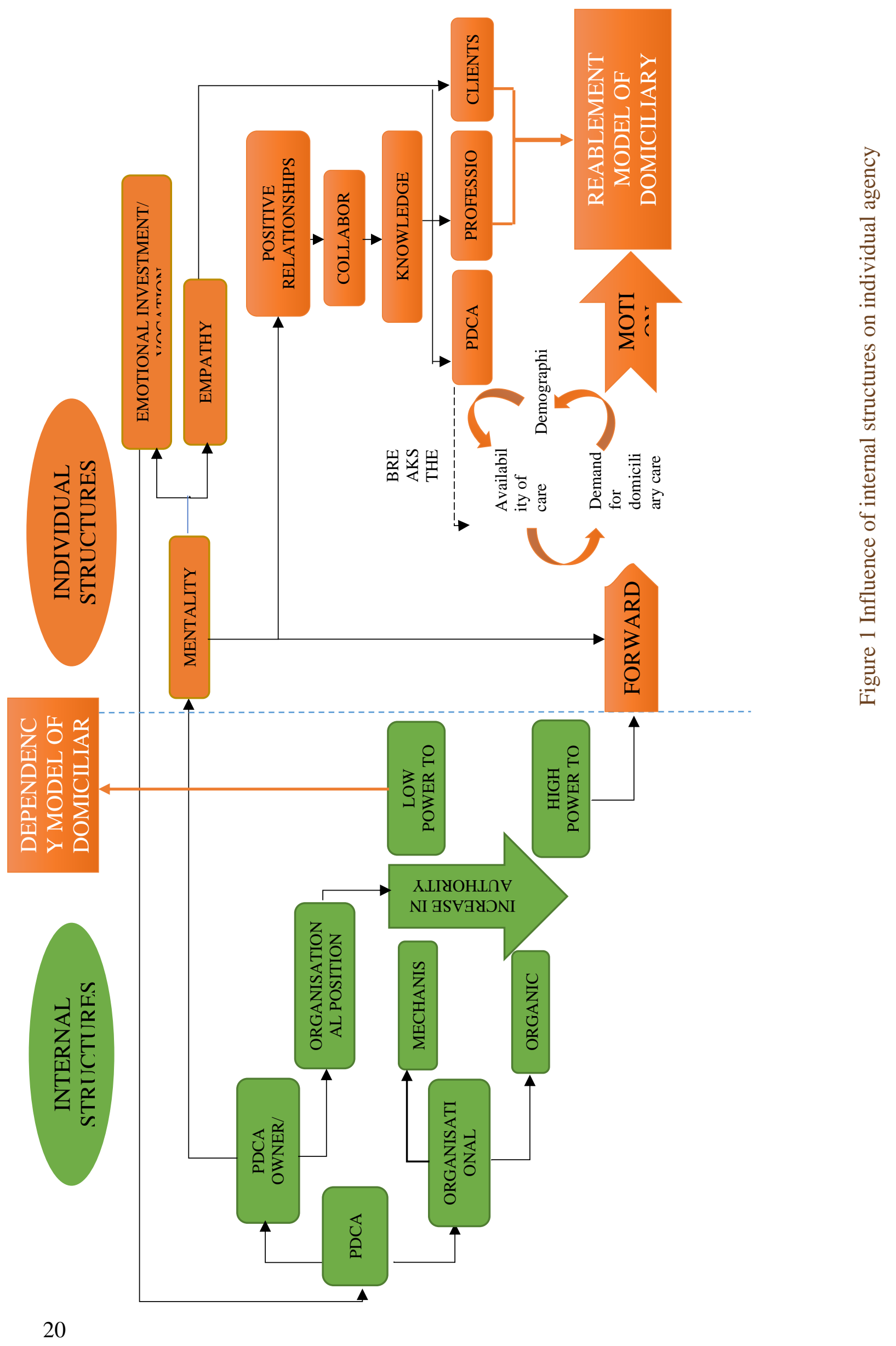




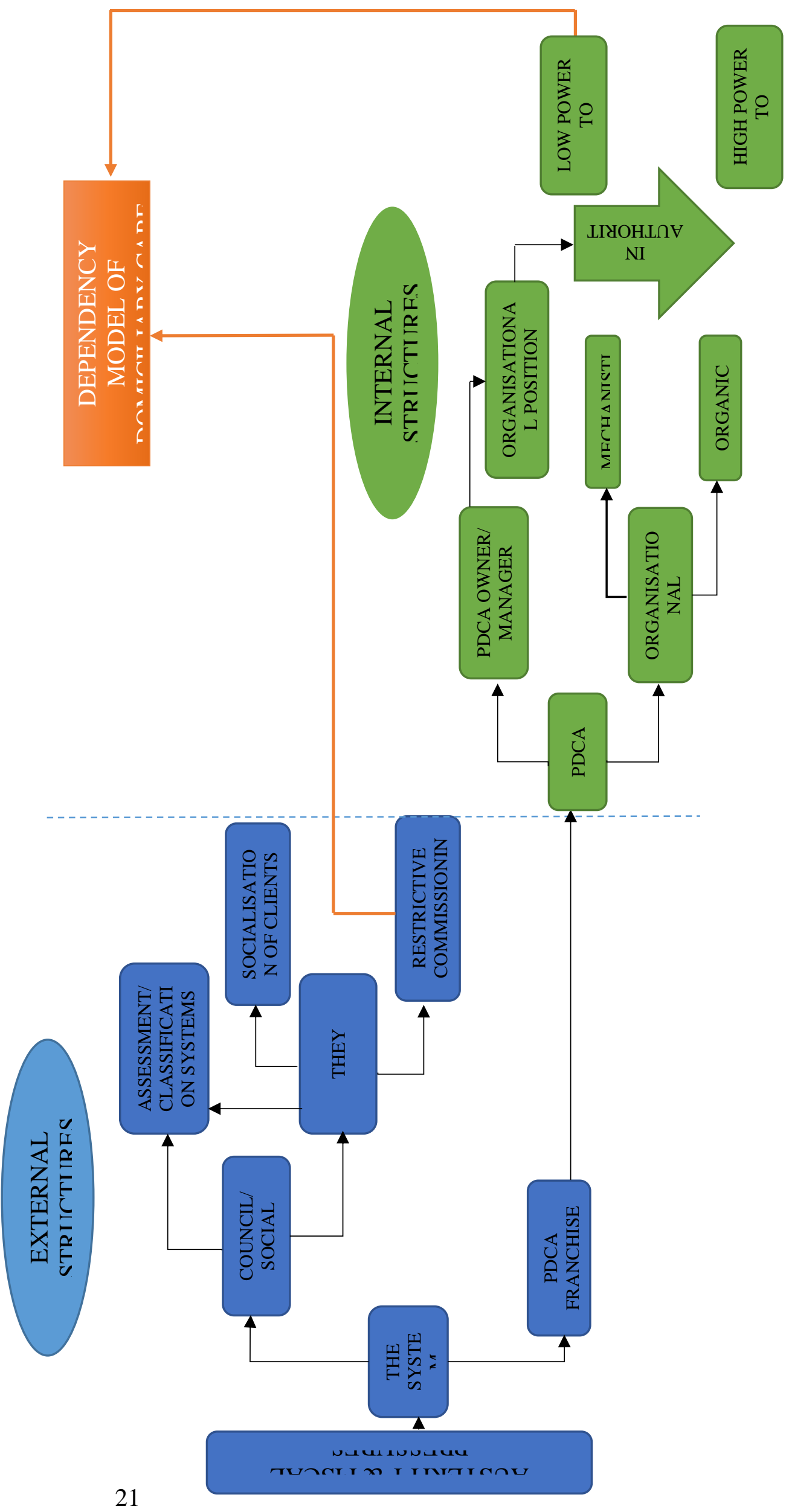

ठิ 


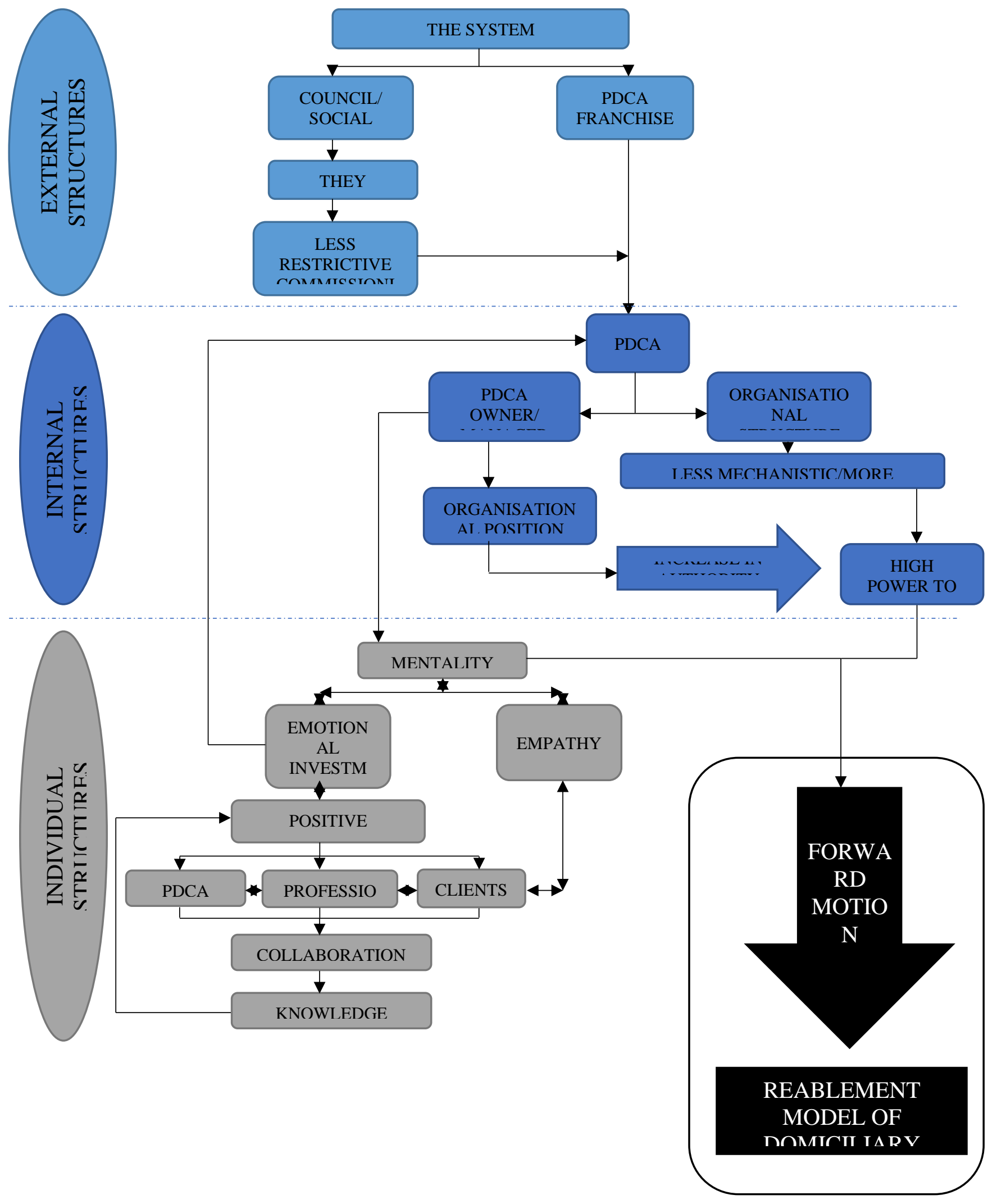

Figure 3 Provisional theoretical model of effecting change toward a reablement model of domiciliary care 
